\title{
THIRD AUSTRALIAN SPECTROSCOPY CONFERENCE
}

$\mathrm{T}$ HE third Australian Spectroscopy Conference was held in the School of Chemistry at the University of Sydney during August 22-24 under the sponsorship of the Australian Academy of Science Spectroscopy Committee. A varied and interesting programme, consisting of 5 invited review papers and 51 research papers, was provided for the 227 participants. In addition, six exhibitors displayed some of the latest developments in spectroscopic equipment. The papers were arranged into sessions on vibrational, theoretical, molecular electronic and resonance spectroscopy with some parallel sessions concerned with instruments and analytical applications, including atomic absorption spectroscopy. After Prof. R. J. W. Le Fèvre had briefly welcomed the participants of the Conference to the School of Chemistry, Prof. N. S. Bayliss officially opened the proceedings on behalf of the Australian Academy of Science and welcomed to the conference the overseas guests, Prof. W. C. Price (King's College, London) and Mr. J. E. Allan (Rukuhia Soil Research Station, Hamilton, New Zealand).

The conference opened with a session on vibrational spectroscopy, and Prof. W. C. Price commenced with a stimulating review of recent developments in the far infra-red. After briefly referring to the experimental difficulties associated with investigations in the range $1-500 \mathrm{~cm}^{-1}$, he then proceeded to discuss the selection of sources, dispersing materials and detectors, and concluded by giving examples of the use of this region to obtain information on rotational energy-level in gases, lattice vibrations in crystalline and molecular crystals, and impurity energy-levels in semi-conductors.

Three research papers then followed dealing with infra-red studies on hydrogen bonding. Prof. A. N. Hambly (Department of Chemistry, School of General Studies, Australian National University) discussed the infra-red evidence for hydrogen-bonding in amino-sulphones, and concluded that stronger interaction occurs between the amino and sulphone groups on adjacent carbon atoms than occurs in the corresponding nitro-amines. This was attributed to the difference in the geometry of the interacting groups. Mr. P. E. Rogasch (Weapons Research Establishment, Salisbury) produced evidence to show that proton transfer can occur in systems that are strongly hydrogen-bonded. Mr. I. H. Reece and Prof. R. L. Werner (Department of Physical Chemistry, University of New South Wales) dealt with the intermolecular interaction between carbonyl and hydroxyl groups in solution, and showed how this interaction can be used to deduce $p K a$ values for the hydroxyl compounds from the infra-red spectrum.

The session continued with papers on analysis of the vibrational spectrum on mono-methyl-arsine (Dr. V. Cranmer, Imperial Chemical Industries, Australia and New Zealand, Ltd., Central Research Laboratories, Ascot Vale), of dichlorofluoromethane. sulphenyl chloride (Dr. N. S. Ham, Division of Chemical Physics, Commonwealth Scientific and Industrial Research Organization) and tri-methyl borate (Prof. R. L. Werner, Department of Physical Chemistry, University of New South Wales). Dr. E. Spinner (Department of Medical Chemistry, Aus- tralian National University, Canberra) discussed the vibrational spectra and structures of the hydrochlorides of the aminopyridines. The Ramm and infra-red spectra suggest that whereas the positive charge resides on the ring nitrogen in 3 -aminopyridine it is located on the amino-nitrogen in 2- and 4aminopyridine. Mr. R. H. Laby and Dr. D. J. Greenland (Waite Agricultural Research Institute, University of Adelaide) were concerned with the implications of the infra-red spectra of molecules of amino-acids, simple peptides, alcohols and glycols adsorbed by montmorillonite. Methods for increasing the discrimination between similar infra-red spectra were described by Dr. J. Tregellas-Williams (Defence Standards Laboratories, Maribyrnong). Progress being made in the development of improved microwave-powered Raman sources was summarized by Dr. N. S. Ham and Dr. A. Walsh (Division of Chemical Physics, Commonwealth Scientific and Industrial Research Organization). The session on vibrational spectroscopy was concluded with a paper by $\mathrm{Dr}$. $\mathrm{P}$. Marmet (Division of Chemical Physics, Commonwealth Scientific and Industrial Research Organiza. tion) dealing with the problem of producing monoenergetic electrons in a mass-spectrometer and their use in obtaining details of the vibrational structure in the energy states of simple molecular ions.

Dr. N. S. Ham (Division of Chemical Physics, Commonwealth Scientific and Industrial Research Organization), in the session on theoretical and molecular electronic spectroscopy, reviewed some theoretical and experimental aspects of the Jahn-Teller theorem. He pointed out how the experimental manifestations of the theorem depended on the magnitude of the distorting forces. Examples showing orbital and/or spin degenerate ground and excited states were discussed. Mr. E. F. McCoy and Dr. I. G. Ross (Department of Physical Chemistry, University of Sydney) considered the change of shape in electronic transitions of polycyclic aromatic hydrocarbons. They showed that encouraging agreornent is obtained with experiment if calculations of the overall width and intensity distribution in the corresponding emission or absorption spectrum are based on the sum of the squares of the bond-length changes that accompany the electronic transition. Mr. J. C. Mackie and Dr. I. E. Lyons, from the same department, outlined theoretical methods which enable the accurate calculation of the ionization potential of a molecular crystal from a knowledge of the ionization potential of the free molecule, its polarizability and the crystal structure. Prof. W. C. Price discussed the ionization potentials of some simple radicals and molecules in terms of their electronic structure. It was shown that the $\pi$ electron orbitais of the halogen substituted $\mathrm{CH}_{3}, \mathrm{CH}_{2}$ and $\mathrm{CH}$ radicals account for the magnitudes of the observed ionization potential and stability of parent molecules and ions. The effects of progressive substitution on the ionization potential of ethylene were also explained.

Dr. E. G. McRae spoke on the theoretical relationship between fluorescence and vibrational structure and Davydov splitting in molecular crystals. Application of his theoretical treaiment to the available information on the crystal fluorescence spectrum of 
anthracene leads to a prediction of a Davydov splitting of the order of $500 \mathrm{~cm} .^{-1}$. It is interesting to compare this with a later paper in the conference in which Mr. A. R. Lacey and Dr. L. E. Lyons (Department of Physical Chemistry, University of Sydney) described experimental investigations of the Davydov splitting in the spectrum of anthracene crystals which yielded an estimate of $\sim 330 \mathrm{~cm}^{-1}$ for this splitting; the much lower values $\left(0-60 \mathrm{~cm} .^{-1}\right)$ usually reported are attributed to the combined effect of incomplete polarization of the incident radiation and the thickness of the crystals used by other investigators.

Mr. M. Batley and Dr. L. E. Lyons (Department of Physical Chemistry, University of Sydney) discussed refinements in the quantitative prediction of the crystal spectrum of phthalocyanine. In a paper by Dr. E. A. Magnusson and Dr. H. Shull (Australian Missionary College, Cooranbong) it was suggested that the barrier to internal rotation about a single bond may be explained both with regard to height and sense, in terms of interactions between the electrons in the terminal bonds and also to the possibility that the distribution of the electrons in the single bond itself is not eylindrically symmetrical. Mr. G. L. White (Defence Standards Laboratories, Maribyrnong) presented a theoretical paper on polarization in Raman spectra. Dr. A. D. Buckingham (Chemistry Department, Harvard) spoke on spectroseopy with polarized radiation. He discussed the existing methods of determining the direction of the transition dipole moment with respect to molecular axes and outlined a new approach involving the measurement of the Kerr constant through absorption bands.

A review by Dr. I. G. Ross (Department of Physical Chemistry, University of Sydney) on optical masers preceded the session on molecular electronic spectroscopy. After explaining the basic principles of optical masers, Dr. Ross considered some of the general and research applications possible for the monochromatic high-intensity beams that can be produced. Dr. T. M. Spotswood (Division of Coal Research, Commonwealth Scientific and Industrial Research Organiza. tion) presented evidence for the formation of charge transfer complexes during the bromination of forms of carbon known to contain relatively high proportions of aromatic structures. The existence of chargetransfer complexes between brominated polycyclic hydrocarbons and halogens in solution was also established, and the spectra of these were compared with those for the corresponding complexes for the corresponding unsubstituted hydrocarbons. In a contribution from Dr. A. V. Bree (University College, London) the fluorescence and absorption spectra in the near ultra-violet of crystals of 9,10-dichloroanthracene, measured at room temperature, were discussed and shown to confirm that the correspond. ing transition in crystalline anthracene is short-axis polarized. Dr. Bree showed that photo-produced impurities accounted for fluorescence and photo conductivity observations. In another paper from the same department, Dr. T. M. Dunn presented the results of a rotational analysis of the $2700 \AA$. system of para-difluorobenzene which confirm that a $B_{3} u \leftarrow A_{3}$ transition (polarized along short axis, that is, in plane of benzene ring and perpendicular to $F-F$ direction) is responsible.

Three papers from the Weapons Research Establishment, Salisbury, were concerned with investigations of the character of the emission associated with various electronic transition processes in flames and in the upper atmosphere. Dr. C. L. Cook and
Mr. J. A. McFarlane described the spectral characteristics of the emission from an ammonia/bromine pentafluoride diffusion flame. Mr. L. J. Drummond and $\mathrm{Mr}$. P. E. Rogasch did the same for the active nitrogen-chloroform and active nitrogen-methylene chloride flames. Dr. J. C. Burns outlined some of the difficulties associated with attempts to measure temperatures from the AlO-radical emission which accompanies the re-entry of the main body of a rocket research vehicle into Earth's atmosphere. Vibrational equilibrium appears to exist and temperatures in the range $1,600^{\circ}-2,000^{\circ} \mathrm{K}$. were obtained.

During the session on analytical applications on emission spectroscopy Mr. L. S. Dale and Mr. R. N. Whittem (Australian Atomic Energy Commission Research Establishment) described the spectrographic techniques in use in health surveys of beryllium contamination. In a second paper, Mr. Whittem discussed the spectrochemical analysis of toxic and $\alpha$-active materials. Mr. A. B. Timms (Australian Mineral Development Laboratories, Adelaide) spoke on the spectrographic determination of hafnium/ zirconium ratios. Mr. J. M. Nobbs (Defence Standards Laboratories, Finsbury) presented evidence to show that while the input of electrical energy to an arc gap between metal electrodes can be controlled to within very fine limits, the output of radiation from the arc column varies randomly from pulse to pulse by factors as large as 200 , and is caused primarily by fluctuations in the evaporation of electrode material. The theory of the photographic characteristic and its use in plate calibration formed the subject of a paper by Mr. C. Candler (South Australian Institute of Technology). The analysis of lubricating oils for the additive elements barium, phosphorus, calcium and zinc with a direct-reading spectrograph was outlined by Dr. R. A. Cummins (Defence Standards Laboratories, Maribyrnong). Mr. I. Collison and Mr. T. Scott (Broken Hill Pty., Newcastle, N.S.W.) spoke on their experiences with the calibration of an A.R.L. 'Quantovac' for the analysis of sulphur and phosphorus in carbon and low alloy steels.

In a session on instruments and techniques the following papers were presented. Mr. J. J. MeNeill (Division of Chemical Physics, Commonwealth Scientific and Industrial Research Organization) discussed factors influencing the design of an inexpensive general-purpose monochromator for use above $2000 \AA$. The construction and performance of an Ebert scanning spectrometer was discussed by Dr. S. C. Baker (Physics Department, Newcastle University College, N.S.W.). A photoelectric device to prevent slow image shifts during long exposures in a high-resolution échelle spectrograph was described by Dr. G. R. Hercus (Division of Chemical Physics, Commonwealth Scientific and Industrial Research Organization). Outstanding problems of instrumentation in the development of the full potentials of X-ray fluorescence spectroscopy as an analytical tool were briefly considered by Mr. J. E. Maloney (Philips Electrical Industries, Sydney). Mr. J. F. Horwood and Mr. D. A. Forss (Dairy Research Section, Commonwealth Scientific and Industrial Research Organization) described methods used for handling microquantities of samples for absorption spectrometry. Mr. F. B. Wunderlich (John Lysaght Pty., Ltd., Newcastle, N.S.W.) indicated how low-resolution infra-red spectra could be used for the identification of constituents in paints and plastics. Mr. A. T. Martin (C.S.R. Chemicals, Rhodes) spoke on the reflectance of opaque materials as a function of pig. 
ment concentration. Finally, Dr. N. Kelso King (Division of Physical Chemistry, Commonwealth Scientific and Industrial Research Organization) discussed the significance of isosbestic points in studying reaction mochanisms.

The session on atomic absorption spectroscopy, which was held on the final morning, proved to be one of the most successful sessions of the conference. It was very gratifying to witness the obvious intense interest in this subject, which was pioneered in Australia and Now Zealand. Mr. J. E. Allan (Rukuhia Soil Research Station, New Zealand) opened this session by reviewing recent developments in the technique. The progress made since the second Australian Spectroscopy Conference in 1959 was amply illustrated by the increase in published research papers from 5 to 50 at present. Dr. B. G. Davey (School of Agriculture, University of Sydney) described the application of atomic absorption spectroscopy to the analysis of agricultural materials. It is now possible to determine rapidly many elements in soil and plant material; up to 170 samples an hour can be analysed for one element with a coefficient of variation less than \pm 5 per cent using very simple equipment. Mr. D. J. David (Division of Plant Industry, Commonwealth Scientific and Industrial Research Organization) discussed the determination of molybdenum by atomic absorption. Molybdenum is believed to be present in a flame as the oxide under normal conditions, but in an acetylene-air flame operated under reducing conditions the molybdenum trioxide dissociates to atomic molybdenum which can be detected by absorption. Mr. David suggested that compound formation under flame conditions may account for many of the interferences that can occur in analysis by atomic absorption. The research in atomic absorption being carried out at present at the Rukuhia Soil Research Station was surveyed by Mr. J. E. Allan. Extension of the range of elements accessible to the technique by the use of nitrous oxide-acetylene flames is being investigated. The determination of cobalt and nickel in agricultural materials has been studied in detail, and procedures established for the analysis of fertilizers. Dr. J. B. Willis (Division of Chemical Physics, Commonwealth Scientific and Industrial Research Organization) showed how atomic absorption was being used to determine traces of heavy metals such as lead, mercury, bismuth, nickel, cadmium and zine in biological materials. The sample preparation procedures are much simpler than those involved in most existing methods; cadmium and zine can be determined directly in urine and preliminary experiments suggest that zinc may be determined in blood serum and whole blood by spraying the diluted material directly into the flame. Cathodic sputtering appears to be an atractive method for atomizing those elements (for example, aluminium, strontium and titanium) which form refractory compounds under flame conditions, and Drs. B. M. Gatehouse, J. V. Sullivan and A. Walsh (Division of Chemical Physics, Commonwealth Scientific and Industrial Research Organization) discussed the factors affecting the cathodic sputtering of various metals. In some instances it has been possible to establish sputtering conditions which permit analytical determinations, but the method is still unsatisfactory for aluminium.

The final session of the conference was devoted to resonance spectroscopy. Dr. G. S. Bogle (Division of Physics, Commonwealth Scientific and Industrial Research Organization) reviewed the development of the theory of electron paramagnetic resonance. Mr. A. J. Harle, Dr. L. E. Lyons and Mr. B. K. Selinger (Department of Physical Chemistry, University of Sydney) summarized the results of a preliminary survey of the electron-spin resonance spectra of some charge-transfer complexes between chloranil and aluminium oxide, hexamethyl benzene and tetracyanoethylene, dibenzacridine and tetracyanoethylene or chloranil. Dr. G. S. Bogle (Division of Physies, Commonwealth Scientific and Industrial Research Organization), Drs. W. F. Forbes and W. E. Savige (Division of Protein Chemistry, Commonwealth Scientific and Industrial Research Organization) reported some investigations of the electron paramagnetic resonance properties of cystine and related compounds after irradiation with mercury $2537 \AA$. radiation and a sun-lamp (peak $\sim 3100 \AA$ A.). Similar spectra are obtained for all the compounds examined, indicating that the same trapped free radical $R \mathrm{~S}$. $\left(R=\mathrm{CH}_{3} \cdot \mathrm{CH} \cdot(\mathrm{NH})_{2} \cdot \mathrm{COOH}\right)$ is formed in each case on irradiation. Mr. T. J. Seed (Department of Physics, University of Canterbury) discussed the paramagnetic spectra of manganous ions in undiluted crystals of the solid-solution ammonium chloridemanganous chloride-water.

In the final paper of the conference Dr. C. K. Coogan (Division of Chemical Physics) and Prof. H. S. Gutowsky (Chemistry Department, University of Illinois) reported on nuclear magnetic resonance in sodium hydrosulphide. Observations on the hydrogen-1 and sodium-23 resonances in polyerystalline samples of sodium hydrosulphide tend to confirm Pauling's hypothesis that the hydrosulphide ion is tumbling very rapidly in the crystal lattice and thus presents an outward spherical form to the surrounding ions. This occurs above $80^{\circ} \mathrm{C}$., and it was also observed that $\mathrm{SH}$-ions can diffuse through the lattice. R. A. DURIE

\section{COLLOIDAL SYSTEMS}

\begin{abstract}
$A^{N}$ $\mathrm{N}$ informal discussion on colloids, under the auspices of the Faraday Society, was held in the Royal College of Science and Technology, Glasgow, on June 27. The meeting was held to mark the centenary of the appearance of Thomas Graham's paper, "Liquid Diffusion applied to Analysis", in which a clear definition of colloids and crystalloids was first given. An attempt was made to cover as many colloidal topics as possible; in the event, this did not prove feasible and the subjects tended to be
\end{abstract}

somewhat biased towards association colloids. About seventy people attended the meeting, including several from Holland.

The chairman, for the morning session, was Prof. P. L. Pauson, who welcomed the visitors to the Royal College and indicated the reasons for holding the discussion at this time and place. (Graham held his first chair at the College.) The first speaker was Dr. A. J. Hyde (Glasgow), who gave a brief biography of Graham with rather greater emphasis on the private 